\title{
REFLECTION
}

\section{The Untaught Lesson}

\author{
Ruth Kannai, MD
}

Department of Family Medicine, Hebrew University, Hadassah School of Medicine, Jerusalem, Israel
Conflicts of interest: author reports none.

\section{CORRESPONDING AUTHOR}

Ruth Kannai, MD

6B Apt. 2 Reuven St. Bet Shemesh Israel 99544

rkannai@gmail.com

\begin{abstract}
My fellow physician and friend died from a rare type of cancer. She was a model for me in many respects. She showed me how to cope with a chronic disease together with a demanding professional life, yet she left me without any comfort or guidelines on how to contend with a terminal disease.

This story is a reflection on my frustration and disappointment with my friend's final choices that prevented us from processing our feelings and sharing our deepest thoughts. The story includes reflections and insights about our ability to understand and accept the preferences of patients and others close to us.
\end{abstract}

Ann Fam Med 2015;13:587-588. doi: 10.1370/afm.1855.

Tremember the very first time I saw you. I was a young intern in a robe heavily laden with work tools and books; you were a senior intern, petite, energetic, standing at the counter of the ambulatory hematologic department. Your voice was captivating: simultaneously funny, cynical, and confident. It would be the beginning of a long relationship with you as my mentor, my colleague, at times my physician, and my cherished friend.

Your family and close friends called you "Tiny." Having met you as an adult, I could never get used to that. You were larger than life.

We both suffered from a chronic disease that we would often discuss. You always knew how to recognize the fact that we had a chronic disease as well as a determination to live with it as best as we were able.

We gave birth to our first-born daughters at the same time. A few years later, you accompanied me to the operation room where I gave birth to my last son. Our friendship extended to our families and children, and was graced by several years of shared happiness. We were both living life in the fast lane.

When I was 40 -something and you were 40 -something and a bit more, illness struck you. The tests revealed a strange and rare growth. We read the diagnosis in disbelief: adenocarcinoma of the biliary tract. Neither of us had ever met such a patient. We both voraciously read anything we could get our hands on about the disease and within a few hours summarized: "Pretty lousy, huh?" to which you added: "Only doctors get such exotic diagnoses."

You sought doctors who could treat the disease, requesting second and third opinions. Despite the horrible prognosis, you grasped onto any treatment that offered hope, anywhere in the world. You used your personal and professional connections to obtain experimental treatments and protocols were invented just for you. There was no previous experience in successfully treating your type of cancer. You were willing to suffer any side effect; you forewent every form of quality of life. You held onto life and onto the anger about life slipping out of your control.

I secretly lost hope from the first moment. I identified with your denial in one respect only: as a mother of two adolescents, you had to do anything possible to get better. You weren't allowed to die. It was inconceivable.

Yet it was impossible to talk openly about these emotions. I longed to tell you: "Irene, you know how our patients sometimes hold onto life and it 
is our job to help them accept that death is approaching, and to tell them that maybe they should focus on pain relief and not recovery, and perhaps they should write their advance directives....? Well, now that patient is you." But I could not be so blunt. The topic was strictly taboo.

I tried to listen to you. Just as you taught me to live with a chronic disease, I thought perhaps you would show me what to do when the battle fails and the disease overtakes unimaginable parts of the body. How does a brave, determined, realistic, and energetic woman like you (and me) deal with a fatal disease?

If I had said the word "fatal" you would have kicked me out of your room and out of your life. There was no room for such conversation. You refused to discuss it, to recognize it. You refused to say goodbye. It was heartbreaking to watch you suffer. I supported transferring to palliative care, but you maintained your battle with the disease with all your might and effort.

For what would be your last birthday I bought you a comic book about cancer (Cancer Made Me a Shallower Person ${ }^{1}$ — written and illustrated by Miriam Engelberg, a woman who used humor to work with her breast cancer, from which she eventually died). You always had a cynical sense of humor and you were one of the funniest people I knew, but "This time," you said, "Ruth, you've crossed the limit. It's like telling a Holocaust joke to a survivor."

I was at a loss of finding a way in, beyond the fortress of denial you imposed on yourself and your surroundings.

We never said goodbye. You never told me what you wanted me to do after your death. You never asked me to take care of your husband and the children. You never said any concluding words, no words of farewell. In the past, we often spoke of the fact that as doctors when we accompanied patients to their death, we were in fact also rehearsing for our own death. You stopped training me during those final days when your impending death lingered in the air.

On a pain-ridden Saturday, with just your husband at your side, you asked for a terminal sedation until your final rest. When I last saw you, you were already sedated, taking away my final chance for a closure you so adamantly wanted to avoid. You left me: a colleague, a friend, with a huge question mark and without any comfort or guidelines as to how to cope with a serious, fatal, hopeless illness.

You could not face the uncontrollable truth, either with yourself or with me, leaving me to contend alone with my own unanswered questions and fears. Perhaps all of my experiences, insights, and resolutions will be of no avail when faced with the threat of losing my own life.

Even as an experienced and empathic teacher, well aware of the dynamics between physician and patient, I realize I can never fully comprehend the factors that converge to ultimately determine a patient's decisions. It is a complex fabric of culture, personality, conditions, community, and family, and there is no formula. I understand that my only remedy is to live life fully with open arms in the hope I will be wise enough to learn how to accept death when it appears.

What I did learn from you, Irene, is about the unknown. I learned this: that I cannot assume that just because we were so similar in education, background, vocation, and coping with a chronic disease, that we would cope with death in the same way.

You taught me by not teaching me. You taught me by leaving me alone to walk this untrodden path.

Your guidance was in reflecting through your example how I would not like to cope with death, yet I fear that I am not immune to such a battle. And you taught me that I simply cannot know how I will cope should I face a similar situation-perhaps I too will fight until the end. Through this, you taught me about humility. There are unknown parts of ourselves that arise when we encounter unknown situations. This is part of what I now try to teach my students - that no matter what knowledge, values, perspectives we hold-to allow for the unknown to surprise us...mold us, shape us, impact us. This is what it truly means to be open to life and death: to agree to not know.

Another untaught lesson you gave me was to learn to accept you unconditionally. Despite my deep disappointment and frustration at not being able to communicate openly with you, I accept this as your final lesson for me. Although I wanted to learn something else, perhaps this was exactly what I needed to learn.

To read or post commentaries in response to this article, see it online at http://www.annfammed.org/content/13/6/587.

Submitted April 1, 2015 ; submitted, revised July 20, 2015; accepted August 6, 2015.

Acknowledgment: I thank Mrs Aya Alon for her assistance in reviewing and editing this manuscript.

\section{References}

1. Engelberg M. Cancer Made Me a Shallower Person. New York, NY: Harper Collins; 2006. 